\title{
PROTEÇÃO DE BLINDAGEM NA LINHA DE INTERFACE ENTRE PLACAS CERÂMICAS*
}

\section{Resumo}

Carlos Frederico de Matos Chagas ${ }^{1}$ Willian Trindade ${ }^{2}$ Edio Pereira Lima Júnior ${ }^{3}$ Guilherme Pinto Guimarães ${ }^{4}$ Sergio Neves Monteiro 5 Aldélio Bueno Caldeira ${ }^{6}$ Luís Henrique Leme Louro ${ }^{7}$ Jheison Lopes dos Santos ${ }^{8}$ Alaelson Vieira Gomes ${ }^{9}$

A blindagem adicional de veículos militares usualmente possui uma camada de placas cerâmicas justapostas e coladas sobre um material dúctil, por exemplo, de aramida ou alumínio. Elas devem propiciar proteção balística em toda sua superfície, complementando a blindagem estrutural dos veículos. Suas placas cerâmicas são relativamente leves e muito eficazes na destruição da ponta de um projétil, no impacto balístico. Contudo, há limitações nesta solução, porque a linha de interface entre as placas é uma região vulnerável, pela ausência de continuidade material ao longo desta linha, onde a eficácia das placas fica mais comprometida, quanto mais próximo da borda uma placa for atingida por um projétil, como mostrado por simulação computacional. Foi desenvolvido um dispositivo cerâmico, à base de alumina com nióbia, com o objetivo de aumentar a proteção ao longo destas regiões vulneráveis. Resultados de ensaios balísticos comprovaram a fragilidade das interfaces e a eficácia do dispositivo desenvolvido.

Palavras-chave: Blindagem; Interface; Balística; Cerâmico

\section{PROTECTION OF ARMOUR IN THE LINE OF INTERFACE BETWEEN CERAMIC PLATES Abstract}

The additional armor of military vehicles usually have a layer of ceramic plates juxtaposed and glued onto a ductile material, for example of aramid or aluminum. They should provide ballistic protection throughout their surface, complementing the structural shielding of the vehicles. Its ceramic plates are relatively light and very effective in destroying the tip of a projectile, in ballistic impact. However, there are limitations in this solution because the interface line between the plates is a vulnerable region, due to the lack of material continuity along this line, where the efficiency of the plates becomes more compromised, the closer to the edge a plate is hit by a projectile, as shown by computational simulation. A ceramic device, based on alumina and niobium, has been developed with the aim of increasing protection throughout these vulnerable regions. Results of ballistic tests proved the fragility of the interfaces and the effectiveness of the developed device.

Keywords: Armor; Interface; Ballistics; Ceramic

1 Engenharia Mecânica e de Armamento, Doutorado em Ciência dos Materiais, Pesquisador, Divisão de Sistemas, Centro Tecnológico do Exército, Rio de Janeiro, RJ, Brasil.

2 Engenharia Química, Doutorado em Ciência dos Materiais, Professor, Curso de Licenciatura em Computação, Universidade do Estado do Amazonas (UEA), Manaus, AM e Brasil.

3 Engenharia Mecânica e de Armamento, Mestrado em Engenharia Mecânica, Aluno de Doutorado, Seção de Engenharia Mecânica e de Materiais, Instituto Militar de Engenharia (IME), Rio de Janeiro, RJ e Brasil

4 Engenharia Mecânica e de Armamento, Doutorado em Ciência dos Materiais, Pesquisador, Divisão de Sistemas, Centro Tecnológico do Exército, Rio de Janeiro, RJ, Brasil

5 Engenharia Metalúrgica, Ph.D. em Ciência dos Materiais, Professor, Seção de Engenharia Mecânica e de Materiais, Instituto Militar de Engenharia (IME), Rio de Janeiro, RJ, Brasil.

6 Engenharia Mecânica, Doutorado em Engenharia Mecânica, Professor, Seção de Engenharia Mecânica e de Materiais, Instituto Militar de Engenharia (IME), Rio de Janeiro, RJ e Brasil.

7 Engenharia Metalúrgica, Doutorado em Ciência dos Materiais, Professor, Seção de Engenharia Mecânica e de Materiais, Instituto Militar de Engenharia (IME), Rio de Janeiro, RJ e Brasil.

8 Licenciado em Física, Doutorado em Ciência dos Materiais (IME), Pós-doutorando, Seção de Engenharia Mecânica e de Materiais, Instituto Militar de Engenharia (IME), Rio de Janeiro, RJ e Brasil

9 Engenharia Metalúrgica, Doutorado em Ciência dos Materiais, Professor, Seção de Engenharia Mecânica e de Materiais, Instituto Militar de Engenharia (IME), Rio de Janeiro, RJ e Brasil. 


\section{INTRODUÇÃO}

As blindagens adicionais normalmente apresentam uma camada de peças cerâmicas justapostas sobre um material dúctil. As dimensões das peças devem obedecer a um compromisso entre a eficiência da peça cerâmica isolada, e a área vulnerável resultante de um impacto sobre uma dessas peças.

Neste contexto, é importante ressaltar que uma dada peça terá maior eficiência, para o mesmo nível de densificação e a mesma microestrutura do cerâmico, quanto maiores forem suas dimensões. No entanto, a área vulnerável após o disparo será do tamanho da peça atingida [1].

Assim, as peças devem possuir as menores dimensões que possibilitem sua utilização com eficiência contra dada ameaça, pelo risco de serem atingidas próximo à borda aumentar com a redução das dimensões da peça.

O material cerâmico básico utilizado neste trabalho é a alumina. Duas características tornam a alumina um dos cerâmicos mais utilizados no mundo para aplicações balísticas: grande disponibilidade e dureza elevada [2].

A facilidade de processamento e a abundância da alumina tornam o seu preço muito competitivo quando comparado a outros materiais cerâmicos utilizados em blindagem, como carbeto de boro e carbeto de silício. No entanto, a alumina apresenta massa específica mais elevada que esses cerâmicos, o que a torna a solução ideal para empregos em que o peso da blindagem não seja um fator crítico, como no caso de veículos blindados pesados [3].

\section{MATERIAIS E MÉTODOS}

Os materiais utilizados foram: alumina tipo APC-2011 SG, com tamanho médio de partícula de $3 \mu \mathrm{m}$; alumina tipo A-1000 SG, com tamanho médio de partícula de 0,3 $\mu \mathrm{m}$; nióbia com tamanho médio de partícula de $0,3 \mu \mathrm{m}$, utilizada como aditivo de sinterização; epolietileno glicol (PEG) de peso molecular 400,como ligante [4] [5].

Para determinação do tamanho médio de partícula foi empregado o analisador de partículas CILAS 1064, que se baseia no espalhamento de laser de fontes sequenciadas e posicionadasa em $0{ }^{\circ} \mathrm{e} 45^{\circ}$.

O processo de fabricação das amostras consistiu na mistura de: $96 \%$ em peso de pó de alumina; $4 \%$ em peso de nióbia; 1,3\% de PEG; e massa de água correspondente à massa total dos demais materiais. Em seguida, a mistura foi colocada em uma estufa para secagem. O pó seco foi desaglomerado e posteriormente peneirado. As peças foram uniaxialmente prensadas por meio do método deum punção móvel e outro fixo com camisa flutuante, sob pressão de $30 \mathrm{MPa}$. O corpo verde foi sinterizado na temperatura de 1400 $\mathrm{C}$ por um período de 3 horas.

A densidade das amostras sinterizadas foi calculada por meio da norma NBR 6220, da ABNT, baseada no princípio de Arquimedes. A medida das massas foi realizada em uma balança digital com aproximação de $1 \times 10^{-3} \mathrm{~g}$ sob temperatura constante.

A análise do tamanho de grão se deu por meio do método das interseções, a partir das imagens obtidas por Microscópio Eletrônico de Varredura com ampliação de 15.000 vezes e aceleração do feixe de $30 \mathrm{keV}$.

Os ensaios balísticos foram realizados no Campo de Provas da Marambaia do Exército Brasileiro, com provete de precisão calibre 7,62 mm e munição calibre 7,62 mm comum. Os disparos foram realizados a uma distância de 15 metros. 
Foram empregadas nos testes balísticos amostras produzidas a partir de composições com a alumina tipo APC-2011 SG para as placas, e alumina tipo A1000 SG para a proteção de interface.

A Figura 1 apresenta a configuração das placas cerâmicas sem proteção de interface e a Figura 2com a referida proteção, coladas com poliuretano (SIKAFLEX) sobre uma placa de 16 camadas de tecido de aramida.

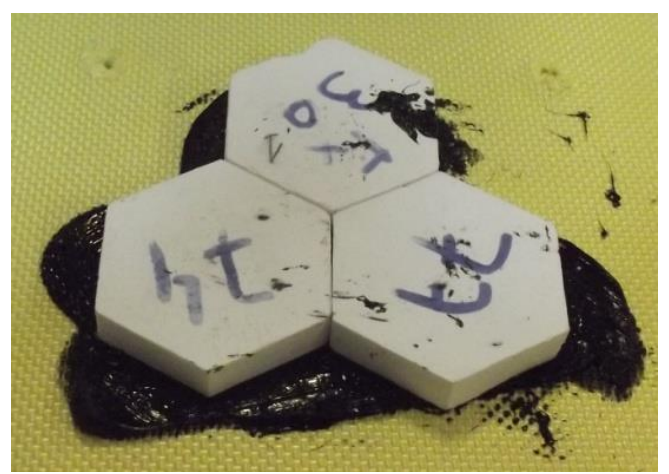

Figura 1. Mosaico cerâmico para blindagemsem proteção na interface

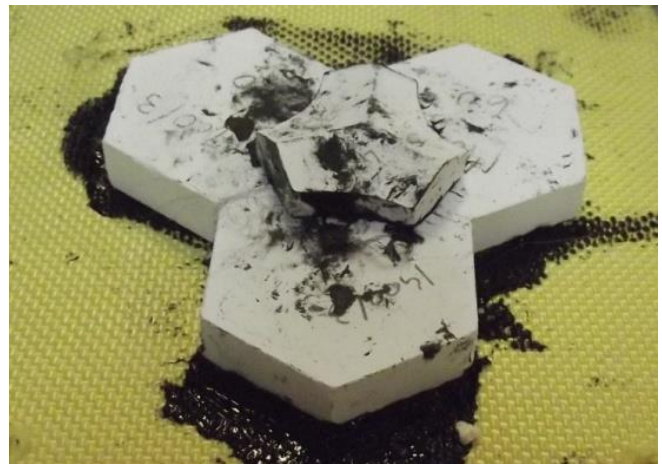

Figura 2. Mosaico cerâmico para blindagemcom proteção na interface

Sobre o cerâmico foram colocadas duas camadas de aramida com a finalidade de reter os fragmentos cerâmicos, visto que a proteção balística proporcionada por essas camadas é desprezível.A Tabela 1 apresenta as características das peças cerâmicas utilizadas nos mosaicos balísticos.

Tabela 1. Amostras utilizadas nos testes balísticos

\begin{tabular}{|c|c|c|}
\hline FUNÇÃO NO MOSAICO & MASSA (g) & TIPO DE ALUMINA \\
\hline Base & 50 & A-1000 \\
\hline Proteção de interface & 18 & APC-2011 \\
\hline
\end{tabular}

A simulação do impacto balístico ao longo da distância do centro da placa base foi realizada fazendo uso do software LS-Dyna, de propriedade do Centro Tecnológico do Exército (CTEx), baseado na análise dinâmica explícita e no método de elementos finitos. 


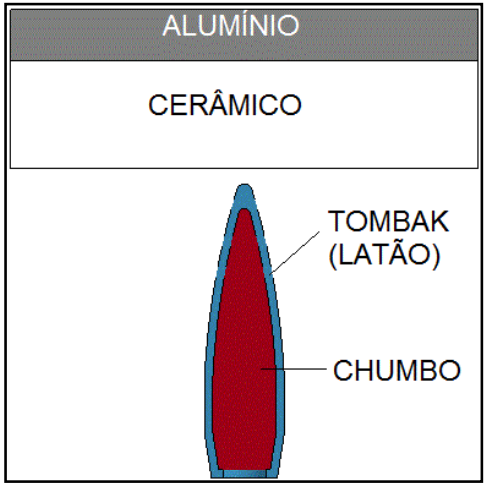

Figura 3. Impacto balístico no centro do alvo

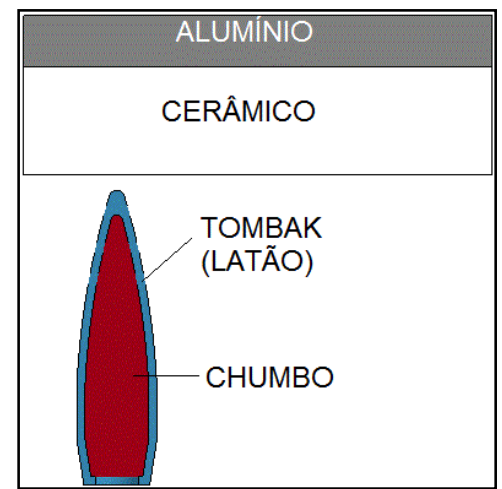

Figura 4. Impacto balístico na metade da distância da aresta ao centro

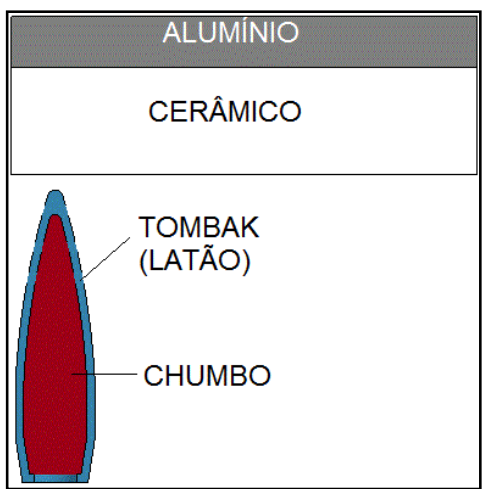

Figura 5. Impacto balístico a 1/4 da distância da aresta ao centro

Assim, foram realizadas as seguintes simulações:impacto balístico no centro de um alvo hexagonal (Figura 3);impacto balístico sobre um ponto na metade da distância entre o centro do alvo e a aresta de um alvo hexagonal (Erro! Fonte de referência não encontrada.); e impacto balístico sobre um ponto a 1/4 da distância da aresta até o centro de um alvo hexagonal (Erro! Fonte de referência não encontrada.).

Devido à complexidade da modelagem computacional, na simulação umaplaca cerâmica hexagonal foi colada sobre uma chapa de alumínio. As interações entre o projétil e as partes constituintes do alvo foram representadas por meio de um algoritmo de contato. Neste algoritmo, considera-se que há contato entre as partes, quando um vetor normal à superfície de um elemento de uma parte intercepta o vetor normal à superfície de um elemento de outra parte. 
O modelo constitutivo de Johnson-Holmquist-2 (JH-2) foi utilizado para a modelagem do material cerâmico. O modelo Plástico-Cinemático foi utilizado para o alumínio e os materiais constituintes do projétil (núcleo + camisa).

\section{RESULTADOS E DISCUSSÃO}

\subsection{Nível de densificação dos cerâmicos}

A densificação alcançada por cada tipo de peça utilizada é apresentada na Tabela 2. Conforme esperado, as peças utilizadas como base, no mosaico balístico, apresentaram nível de densificação maior do que as peças utilizadas para a proteção de interface, pois a composição utilizada na sinterização das primeiras se baseia em alumina com menor tamanho de partícula e, consequentemente, maior força motriz para sinterização, em virtude de possuir maior área superficial [6].

Tabela 2. Massa específica e nível de densificação das amostras cerâmicas

\begin{tabular}{|c|c|c|}
\hline $\begin{array}{c}\text { Tipo de Peça } \\
\text { (função no mosaico) }\end{array}$ & Massa Específica $\mathbf{( k g / \mathbf { c m } ^ { 3 } \text { ) }}$ & $\begin{array}{c}\text { Densificação } \\
\text { (\% densidade teórica) }\end{array}$ \\
\hline Base & $3,79 \pm 0,04$ & $94,67 \pm 0,87$ \\
\hline Proteção de interface & $3,55 \pm 0,02$ & $88,66 \pm 0,47$ \\
\hline
\end{tabular}

\subsection{Tamanho de grão das amostras}

A Tabela 3 apresenta a medida do tamanho de grão, calculado pelo método das interseções, com base em amostras retiradas de 3 peças produzidas utilizando-se a composição 1 (Figura 6) ou a composição 2 (Figura7).

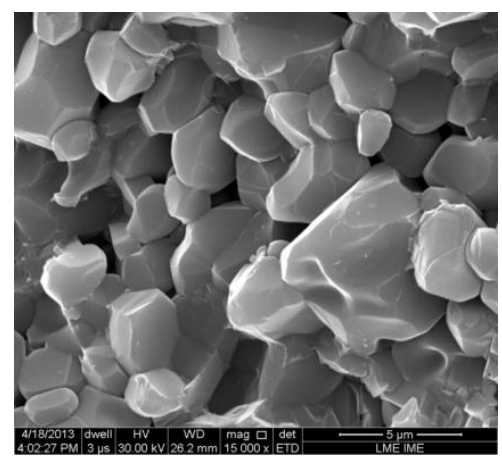

Figura 6. Microestrutura de peças sinterizadas com a composição 1

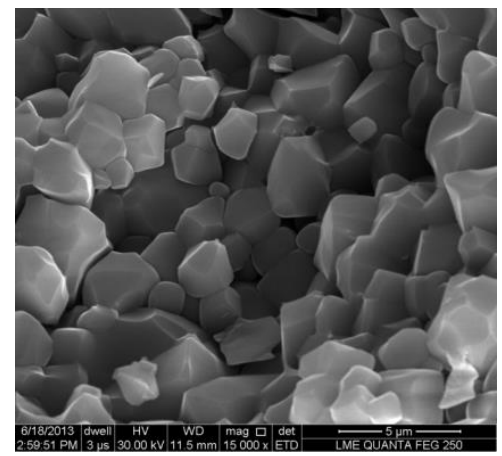

Figura 7. Microestrutura de peças sinterizadas com a composição 2 
Observa-se que o tamanho médio de grão calculado para as peças da composição 2 é aproximadamente a metade do valor do tamanho médio dos grãos das peças da composição 1. Na sinterização, a redução da energia livre do sistema ocorre por meio de dois mecanismos que competem entre si: (1) a densificação associada à eliminação de poros; e (2) o crescimento de grão.

O tamanho médio das partículas na composição inicial exerce grande influência no processo de sinterização, visto que há mais energia de superfície livre para as composições com menor tamanho médio [6].

Tabela 3 - Tamanho de grão das placas cerâmicas

\begin{tabular}{|c|c|c|}
\cline { 2 - 3 } \multicolumn{1}{c|}{} & Base & Proteção de interface \\
\hline Tamanho médio dos grãos $(\mu \mathrm{m})$ & 3,17 & 1,61 \\
\hline Desvio Padrão $(\mu \mathrm{m})$ & 0,20 & 0,20 \\
\hline
\end{tabular}

\subsection{Ensaio balístico}

Os alvos foram apoiados sobre a plastilina e, então, submetidos ao impacto de projétil 7,62 $\mathrm{mm}$ a uma distância de 15 metros.

A tabela 4 apresenta os resultados obtidos para os mosaicos com e sem proteção de interface para impacto na interseção entre três peças. Observa-se que os mosaicos sem proteção de interface foram perfurados e aqueles com a proteção de interface resistiram ao impacto.

Tabela 4. Resultados dos testes balísticos

\begin{tabular}{|c|c|c|}
\hline $\begin{array}{c}\text { Proteção de interface } \\
\text { (sim/não) }\end{array}$ & $\begin{array}{c}\text { Velocidade } \\
\text { (m/s) }\end{array}$ & $\begin{array}{c}\text { Perfuração completa } \\
\text { (sim/não) }\end{array}$ \\
\hline Não & 835 & $\mathrm{~S}$ \\
\hline Não & 830 & $\mathrm{~S}$ \\
\hline Não & 836 & $\mathrm{~S}$ \\
\hline Sim & 826 & $\mathrm{~N}$ \\
\hline Sim & 833 & $\mathrm{~N}$ \\
\hline Sim & 834 & $\mathrm{~N}$ \\
\hline
\end{tabular}

\subsection{SIMULAÇÃO BALÍSTICA}

Por meio do programa para computador LS-Dyna, foi realizada a simulação de impacto balístico com danosdo material cerâmico sob impacto de um projétil 7,62mm comum no centro (Figura8) e fora do centro do alvo, a uma distância correspondente à metade da distância do centro do alvo a sua borda (Figura9) e a 1/4 desta distância medida a partir da borda (Figura10).

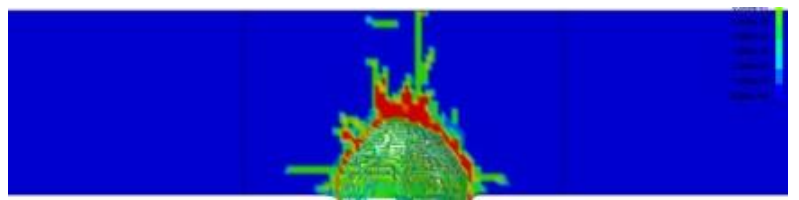

Figura 8. Impacto no centro do alvo 


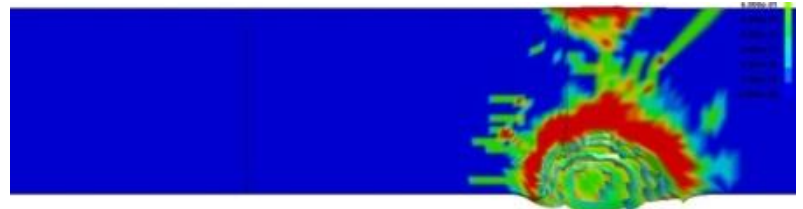

Figura 9. impacto na metade da distância da borda ao centro do alvo

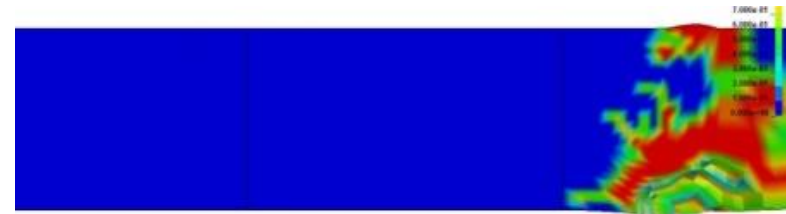

Figura 10. Impacto a um quarto da distância da borda ao centro

Pode-se observar que o dano provocado no cerâmico, no caso do impacto fora do centro, é substancialmente maior que aquele observado para impacto no centro do alvo (região em vermelho). Segundo o modelo de Johnson-Holmquist, a resistência oferecida pelo material das áreas em vermelho, já danificada, é menor que aquela do material das outras áreas.

Comparando-se o nível de dano do material atingido mais próximo à borda, com regiões mais internas conclui-se que a proteção de interface é importante para que a espessura de toda placa não ser superestimada para aumentar a proteção próximo à linha de interface entre estas placas, o que está de acordo com as observações experimentais deste trabalho e com a literatura [1].

\section{CONCLUSÃO}

No decorrer do trabalho, constatou-se que a introdução de um dispositivo de proteção de interface, sobre um mosaico balístico cerâmico, reduz o efeito de aresta e confere maior resistência balística a um mosaico cerâmico com peças com dimensões reduzidas.

Os resultados obtidos nas simulações realizadas concordam com aqueles previstos na literatura, mostrando o aumento do dano da placa cerâmica à medida que o impacto a atinge mais próximo de sua borda.

\section{REFERÊNCIAS}

1 HAZELL PJ, ROBERSON CJ e MOUTINHO M. The design of masaic armour: the influence of the tile-size on the ballistic performance. Materials and Design. 2008. 28(8):1497-1503

2 ASSIS JMK.Estudo comparativo de compósitos alumina-zircônia tetragonal e de cerâmicas de alumina aditivadas com nióbia para aplícações estruturais. Tese de Mestrado - INPE. São José dos Campos. 2007.

3 JAMES B. Practical issues in ceramic armor design. Ceramic Armor Material by Design.2002; 134: 23-31

4 TRINDADE, WILLIAN. 2012. Influência da geometria e da microestrutura no comportamento dinâmico da alumina aditivada com nióbia. Rio de Janeiro : INSTITUTO MILITAR DE ENGENHARIA, 2012

5 GOMES AV. Comportamento balística da alumina com adição de nióbia e variação da geometria do alvo. Tese de doutorado - IME. Rio de Janeiro. 2004.

6 REED JS. Principles of Ceramics Processing. New York: John Wiley \& Sons; 1995. 